\title{
A BASE DE LOGÍSTICA DE DEFESA, INOVAÇÃO E INDÚSTRIA NACIONAL: O PROSUB E A ANÁLISE CIENTÍFICO-TECNOLÓGICA EM ESTUDO COMPARADO DE BRASIL E FRANÇA
}

\author{
Luiz Ricardo Silva Ferreira \\ Clube de Engenharia/Divisão Técnica de Ciência e Tecnologia. (DCTEC) \\ Av. Rio Branco, 124, Centro, Rio de Janeiro/RJ \\ afcric@yahoo.com.br
}

\begin{abstract}
RESUMO
A proposta de artigo científico contempla a constituição da Base de Logística de Defesa no Brasil. Neste contexto, o tema relativo à Logística e Planejamento de Defesa no ambiente marítimo, realiza a seguinte proposição: O PROSUB, como Programa de Estado, assegurando a partir desta premissa, a construção de uma ampla legitimidade institucional, ao atuar como meio necessário à Proteção, Segurança e Defesa do País. Assim, a força naval submarina, contribuiria ao desenvolvimento de ações proativas de Comando e Controle, bem como avaliar e mensurar, entre os quais, a possibilidade de Modelagem do Programa AERODEFESA operacionalizado pela FINEP, a fim de oferecer instrumentos ao fomento, incremento e inovação dual à Indústria de Defesa Nacional. O Estudo de caso comparado entre Brasil e França, junto com a Modelagem demonstrada acima, torna-se exemplo ímpar, de eficiência, eficácia e efetividade ao resgate da Engenharia, Ciência e Tecnologia e Industrialização em benefício da sociedade e da Soberania Nacional.
\end{abstract}

Palavras Chaves: Logística de Defesa, Modelagem e Inovação, Submarinas Brasileiras.

\begin{abstract}
The proposition of this scientific article refers to the logistics base of defense in Brazil. In this context the theme concerning to the logistics and planning of Defense in the maritime environment, propose the development of the PROSUB as a State Program giving it a large institutional legitimacy and acting to the Proctection, Safety and Defense of the country.

So the Submarine Naval Force would cooperate to the development of the proactive actions of command and control as well as would evaluate and measure the possibility of the AERODEFESA Program introduced by FINEP to offer means to fomentation, increase and innovation to the National Defense Industry.

The study of a case compared between Brazil and France with the molding presented above it is an example of efficiency, efficacy and effectiveness to the Engineering, Science y Technology and Industrialization for the benefit of Society and National Sovereignty.
\end{abstract}

Keywords: Logistics of Defense, Model y innovation, Submarine Brazilian 
FERREIRA, Luiz Ricardo. A Base de Logística de Defesa, Inovação e Indústria Nacional: O PROSUB e a análise científico-tecnológica em Estudo Comparado de Brasil e França. In: SIMPÓSIO DE PESQUISA OPERACIONAL E LOGISTICA DE MARINHA, 19., 2019, Rio de Janeiro. Anais, Rio de Janeiro: Centro de Análises de Sistemas Navais, 2019.

\title{
1. INTRODUÇÃO
}

O desenvolvimento de ações proativas de Comando e Controle na Base de Logística de Defesa torna-se imprescindível em razão do Entorno Estratégico demarcado entre as regiões da América do Sul e Atlântico Sul, por meio da inserção do Programa de Submarinos de Modelagem Tradicional e de Propulsão Nuclear como efetivo Programa de Estado no Brasil. O Planejamento em Defesa Nacional define-se conceitualmente, conforme Palestra realizada pelo Prof. Eduardo Brick:

\begin{abstract}
"Por preparo da defesa entende-se o desenvolvimento e a sustentação de capacidades operacionais de combate e, também, industriais e tecnológicas específicas para defesa. Essas duas capacidades são providas pelos dois principais Instrumentos da Defesa: as Forças Armadas (FFAA) e a Base Logística de Defesa (BLD). Esta última agrega, do lado da oferta, não só capacidade industrial e tecnológica para defesa, mas também serviços de apoio às operações e recrutamento e qualificação de recursos humanos. Do lado da demanda, a BLD é quem gerencia todos os processos de desenvolvimento e aquisição de produtos e tecnologias para defesa. A gestão estratégica da defesa é a atividade que envolve a integração do desenvolvimento e sustentação desses dois instrumentos estratégicos (FFAA e BLD), com base nos recursos disponibilizados pelo Poder Político no orçamento de defesa. O planejamento da defesa e sua execução, que resulta no preparo, é o principal produto da gestão estratégica da defesa. A engenharia tem um papel proeminente e insubstituível em todas as fases do planejamento e preparo da defesa." (BRICK, 2019).
\end{abstract}

Neste contexto, planejar em tempos de Paz, significa identificar as reais necessidades de base operacional ao combate disuasório, diante as novas ameaças na Era da Robótica, em como impulsionar uma Base de Logística de Defesa Nacional aliada a Indústria de Inovação em Média e Alta Tecnologia a favor dos interesses do País.

\section{2-PROBLEMA:}

No século XXI, três fatos impactaram o planejamento estratégico em Políticas de Defesa Nacional: o surgimento da Era do Conhecimento, a emergência do Brasil como Nação de grande relevância no cenário mundial e a Imprevisibilidade marcante dos conflitos da atualidade caracterizada por diferentes tipos de ameaças ao redor do mundo. Por outro lado, o fenômeno da "Guerra"1 no mundo contemporâneo retomou características incomuns durante o século XX, sem por sua vez, invalidar as questões de Segurança, Defesa e Proteção.

Por outro lado, o fenômeno da "Guerra"2 no mundo contemporâneo retomou características incomuns durante o século XX, sem por sua vez, invalidar as questões de Segurança, Defesa e Proteção. 
Para o Prof. Francisco Carlos $^{3}$ na conferência da I ENGEOP ${ }^{2}$ em 08/05/17 na EGN ${ }^{2}$, este identifica os seguintes aspectos de Geopolítica e Segurança Internacional na Era Trump, em conferência na Escola de Guerra Naval:

"Paralisia da ONU, ausência de iniciativas do G7, G20, Rodada de Doha e OMC, desarticulação da UE com o MERCOSUL e o surgimento do fenômeno do Brexit com o desemprego estrutural, bem como novas remodelagens geoeconômicas entre países." ${ }^{3}$ (Teixeira da Silva, F.C, 2017)3.

Assim, as inovações científico-tecnológicas da atualidade, em especial, a desenvoltura da Tecnologia da Informação e Comunicação, fizeram surgir o que se denominou a Era do Conhecimento cujas características marcantes são: a maior velocidade, confiabilidade e baixo custo de transmissão e armazenamento de conhecimentos, bem como a outros tipos de informação.

Contudo, a difusão de tais premissas ocorre em qualquer recanto do planeta, podendo afetar a Soberania Nacional e os segredos industriais e geopolíticos, bem como acarretar em desrespeito a garantias individuais e coletivas, podendo afetar a formulação de Políticas Estratégicas de cada país, incluindo o Brasil.

Em contexto de Tempos de Paz, cresce o emprego da logística de defesa, por meio de uma busca do desenvolvimento de Estratégias de Defesa voltadas a dissuasão, mesmo com limitações nas capacidades militares e no próprio processamento de Gestão no âmbito científico-tecnológico e de inovação.

1-Brick, Eduardo, "O Papel da Engenharia no Planejamento e Preparo de Defesa”, Academia Nacional de Engenharia e Clube de Engenharia, 29/07/2019, Auditório do 22 Andar, Clube de Engenharia, 2019.

2-Nota Explicativa 05/12 CLAUSEWITZ, Carl Von: "Da Guerra” - São Paulo: Editora Martins Fontes, 1979.p. 87-89 e JOMINI, Antoine Henri de, Baron. The Art. lhe War, London; Greenhill Books, 1992.p.25-35.

3-Encontro Acadêmico de Geopolítica realizado na Escola de Guerra Naval em 08 de maio de 2017

Neste sentido, o Prof. Brick ${ }^{5}$, identifica e enumera os aspectos essenciais em Planejamento de Defesa ,bem como a perspectiva de construção institucional, em perspectiva da Base de Logística de Defesa: 
- Restrições orçamentárias obrigam a uma busca permanente por uma maior eficiência na alocação dos recursos financeiros;

- Necessidade de adequação na estrutura de defesa à postura estratégica do país, definida pelo poder político;

- Inovação no campo das ciências da administração, resultando em maior eficácia e eficiência na gestão das empresas e órgãos públicos;

- Aceleração do desenvolvimento tecnológico, causando, por um lado, a obsolescência precoce de sistemas de defesa e, por outro lado, propiciando o aparecimento de tecnologias de defesa capazes de influir decisivamente nos conflitos; e.

-Aumento contínuo do custo dos sistemas de Defesa. ${ }^{5}$ ( BRICK, p.06)

Neste diapasão, como mensurar a projeção institucional da Base de Logística de Defesa, acerca das capacidades militares dissuasórias por parte do Brasil no Atlântico Sul, de forma a avaliar a eficiência, eficácia e a efetividade de meios necessários, em ambiente de escassez de recursos orçamentários, humanos e tecnológicos?

\subsection{OBJETIVO GERAL:}

Desenvolver ações Proativas de Comando e Controle na Base de Logística de Defesa, em razão dos entornos Estratégicos demarcados entre América do Sul e Atlântico Sul por meio do Programa PROSUB.

\subsection{OBJETIVOS ESPECÍFICOS:}

-Identificar e empregar os conceitos contemporâneos de Logística de Defesa ao objeto de pesquisa em termos de Planejamento Estratégico e em Gestão de Defesa;

-Analisar a Economia de Defesa, Orçamento em Defesa e a Logística de Defesa, a luz da Inovação em perspectiva comparada, sob o aspecto de resgate da Engenharia, Ciência e Tecnologia e Industrialização;

- Avaliar a Modelagem do Programa AERODEFESA ${ }^{4}$ (FINEP) ao Programa PROSUB para o fomento, incremento e inovação dual à Indústria de Defesa Nacional na fabricação dos tipos Submarinos Convencionais e de Propulsão Nucleares Brasileiros.

\section{CONTRIBUIÇÃO DA PESQUISA AOS ESTUDOS DE SEGURANÇA INTERNACIONAL E DEFESA NACIONAL:}

O objeto proposto em artigo científico vincula-se a contribuição científica aos Estudos de Políticas, Estratégias e Planejamento de Defesa- O Atlântico Sul e o Poder Dissuasório no Mar por meio do PROSUB. ( Programa Brasileiro de Submarinos)

O Atlântico Sul-

"O Objeto do Estudo foi retirado do Livro Branco de Defesa que delineia, no país com a maior costa atlântica do mundo, o Brasil, tem por todas as razões citadas, especial interesse na paz e na segurança do Atlântico Sul. Esse Oceano possui áreas estratégicas relevantes, como a Garganta Atlântica, entre a costa do Nordeste Brasileiro e a África ocidental, espaço intercontinental de vital importância para o comércio mundial. Cumpre ressaltar, ainda a significativa 
importância da vasta bacia petrolífera existente na plataforma continental brasileira, além das rotas de importação de petróleo de países da faixa equatorial do atlântico. As áreas marítimas estratégicas de maior prioridade e importância para o Brasil são representadas pelas águas jurisdicionais brasileiras (AJB), as quais incluem o mar territorial (MT), as zonas contíguas (ZC), a zona econômica exclusiva (ZEE) e a plataforma continental (PC), bem como a região compreendida entre o Paralelo 16 norte, a costa oeste da África, a Antártida, o leste da América do Sul" (Brasil. LBDN, p.39).

\subsection{O Poder Dissuasório no Uso do Mar como meio necessário à Proteção, Segurança e Defesa Nacional:}

"Para assegurar o objetivo de negação ao uso do mar, O

Brasil contará com a força naval submarina de envergadura, composta de submarinos convencionais e os de

propulsão nuclear. O Brasil manterá e desenvolverá sua capacidade de projetar e de fabricar tanto submarino de propulsão convencional, como de propulsão nuclear." ${ }^{6}$

(Brasil, END, p.21)

4-Nota Explicativa:O Programa AeroDefesa fora criado em 2013,como parte do Plano Inova Empresa, sendo instituído pelo Plano de Apoio Conjunto INOVAAERODEFESA. O Plano de apoio Inova Defesa foi uma iniciativa conjunta das Estatais FINEP, BNDES, Ministério da Defesa e Agência Brasileira Aeroespacial.

5-BRICK, Eduardo, "Base de Logística de Defesa-Conceituação, Composição e Dinâmica de Funcionamento", artigo científico, UFF, 2016.

4 REFERENCIAL TEÓRICO: O início de construção das correntes teóricas expostas, por meio do problema da pesquisa pelos Paradigmas Clausewitziano ${ }^{7}$ e Jominiano ${ }^{14}$, servindo de alicerce ao tema da pesquisa: "Estudos acerca da dinâmica industrial e de inovação da Base de Logística de Defesa Nacional.” Enumera-se, então, a importância do Estado e da legislação aos Estudos de Defesa Nacional, por Clausewitz?

Existem certas limitações auto impostas ou imperceptíveis, vinculadas à força, que mal merecem ser mencionadas, como a legislação e os costumes internacionais, mas elas pouco enfraquecem. A força, isto é, a força física porque a força moral não possui existência a não ser como expressão no Estado e na legislação, constituindo como o meio que dispõe à Guerra. Impor a nossa vontade ao inimigo constitui o seu propósito. ${ }^{7}$ (Clausewitz, p.75)

John Keagan ${ }^{8}$, critica a visão clausewitziana, pelo viés da Cultura na seguinte forma:

"Guerra não é a continuação da Política por outros meios." Igualmente, faz a seguinte abordagem acerca das instituições e leis: "Nossas instituições e Leis, dizemos para nós estabeleceram tantas restrições à potencialidade a violência que na nossa vida cotidiana, irão apoiá-la como criminosa, enquanto sua utilização pelas instituições de Estado tomará a forma particular de guerra civilizada. ${ }^{8}$ (Keagan, p.11mesmos, humana para 12).

Assim, para o Autor ${ }^{8}$ existiriam dois tipos de humanos antitéticos, que limitariam a "Guerra Civilizada": O pacifista e o portador legal de armas. Por outro lado, inaugura-se a Trindade Clausewitziana na História pelo Prof. Raymond Aron.

Definição Monista, Dualista e Trinitária. A primeira é encontrada em suas primeiras obras, tal como os Princípios da Guerra e pressupõe que a guerra é a derrubada política e a destruição militar. A definição dualista baseia-se na compreensão resultante de seus estudos históricos de que as guerras são muito diferentes em sua 
intimidade e em seu desenvolvimento para que o princípio do aniquilamento possa explicá-las. Clausewitz compreendeu uma teoria da guerra, devendo abranger todos os tipos de guerra, até mesmo aquelas que não correspondiam ao que parecia ser a essência da guerra. ${ }^{9}$ (Aron, p.136)

A Teoria da Guerra e do Paradigma da Guerra de Clausewitz ${ }^{7}$, aplicável ao Século XXI. Em Howard ${ }^{10}$ :

Não devemos ler coisas demais em Clausewitz, nem devemos esperar dele mais do que pretendeu dar. A dimensão de seu gênio continua sendo que, embora para a qual escrevesse já tenha passado muito tempo, ele pode ainda fornecer tantas ideias pertinentes a uma geração cuja natureza dos problemas ele não poderia ter previsto.

${ }^{10}$ (Howard, p.47)

Clausewitz ${ }^{7}$ e as Novas Guerras no século XXI.

Posição Favorável: Hew Strachan ${ }^{11}$ - o autor abriu a possibilidade para a inserção da trindade clausewitziana para as "novas guerras", pois o conceito do General Prussiano poderá modificar o seu caráter mediante o contexto político, histórico e social de cada tempo, sendo que a natureza da guerra é balizada por um conjunto de forças sociais e pelo espírito de sua época. Diniz, ${ }^{12}$ ao analisar a formação do Estado de Israel, confirmou a atualidade em Clausewitz ${ }^{7}$ :

Por fim, viu-se acima uma corroboração do excedente de conteúdo empírico do programa clausewitziano, ao se identificar historicamente uma sociedade, que não tinha nenhum elemento que pudesse identificá-la como um Estado, sequer arcaico sofrendo uma transformação política e cultural decorrente de um desafio político interno. ${ }^{12}$ (Diniz, p.82)

Posição Desfavorável ao Paradigma Clausewitziano:

Mary Kaldor $^{13}$ - A autora sustenta a tese de que não haveria contemporaneidade em Clausewitz ${ }^{7}$, uma vez que a guerra não seria mais um fenômeno de política interestatal, sendo que cada vez mais aquela não encontraria vazão ao controle estatal. Ademais, as guerras do século XXI, não mais teriam a influência e dinâmica interna, da trindade clausewitziana, seja pela inserção de novas tecnologias bélicas, seja por não serem mais norteadas por um povo, exército ou governo. Para a autora, "as novas guerras", buscariam outras guerras, devido ao enfraquecimento da dimensão Estatal.

O Paradigma Jominiano:

Neste sentido, Jomini ${ }^{14}$ em Sumário de Arte da Guerra, enfatiza o papel da Logística, como uma das 05 ferramentas básicas para condução do Fenômeno da Guerra, sob novos parâmetros entre as quais: A Estratégia, a Grande Tática, A Engenharia (Construção de Fortificações) e a Tática Menor.

Assim, o PROSUB por meio de um Paradigma Jominiano à Engenharia ${ }^{14}$, tornou-se um exemplo efetivo na construção de novos meios em Defesa, entre os quais; a pesquisa, o desenvolvimento e a inovação de cadeias produtivas em Logística de Defesa. Já o Prof. Antônio Cunha Campos ${ }^{15}$, enumerou o desenvolvimento conceitual da Logística de Defesa:

"Destacam-se o desenvolvimento da Logística dentro do âmbito militar, que desde o início foi encarado como uma função meramente operacional, concentrando-se apenas nas atividades administrativas relativas ao deslocamento no acampamento e alojamento das tropas em campanha. Dentro de seu estágio de evolução, esse conceito foi revisto $\log$ na $\quad 1^{\text {a }} \quad$ Guerra Mundial." "15 (Cunha Campos, p.39).

Para o Prof. Eduardo Brick ${ }^{16}$, resgata importante obra do Oficial da U.S. Marine Corpus, dos Estados Unidos da América realizada em 1917, Thorpes, C ${ }^{176}$ Pure Logistics, The Science of War Preparation.”.

“A Concepção Logística de Thorpe e similar ao de Jomine: 
Estratégia e Tática constituem a condução da guerra (o emprego de poder); logística provê os meios. Mas estes não são limitados às funções estreitas de transporte e suprimento. Logística, enfim tudo aquilo que pode ser computado como parte da guerra." ${ }^{17}$ (BRICK, p. 309).

Já a Atualidade de Jomini ${ }^{14}$ a Thorpe ${ }^{17}$, em Logística de Defesa, fora extraída em artigo sob o tema "Base Logística de Defesa" do Prof. Brick"

"Logística incluiu a preparação de" todo o material necessário para colocar os exércitos em movimento; emissão de ordens iniciais e subsequentes; provisão para segurança e reconhecimento; movimentação e sustentação das tropas; estabelecimento de acampamentos; depósitos e linhas de suprimento; organização dos serviços médicos e de comunicações e uma pletora de outras tarefas de administração (Texto de Stanley Falk na Introdução da terceira edição do Livro de Thorpe Tradução do Prof. Eduardo BrickTHORPE, pag. 18, 1996) ${ }^{18}$ (BRICK, p.307).

O Conceito Estratégico Contemporâneo Chinês, Instituições e as Novas Guerras: As Projeções Institucionais em Políticas, Estratégias e Planejamento em Defesa ao século XXI.

Os autores Liang e Chang ${ }^{19}$, trabalharam com novas abordagens conceituais e metodológicas nos níveis Estratégico e Operacional, através de alianças fluidas, campos de batalha indistintos, ações irrestritas, onipresença na informação e caracterização pelo conflito contínuo em todos os meios.

“- Emprego dos Conceitos de" "Hard Power" e "Soft Power" aos níveis político, estratégico, operacional e tático, advogando meios militares e não militares, através da violação do centro de gravidade adversário por simulação de um confronto entre EUA e China;

-A Legitimidade como valor persuasivo no contexto internacional;

-Introdução de Fatores Indiretos no Paradigma da Guerra Limitada à Ilimitada;

-O Estudo do Fenômeno da Guerra e sua natureza, com novos focos de compreensão metodológico e epistemológico em estudos de casos;

-O emprego do Material de Defesa no Pós-Guerra Fria;

-O Guerreiro Não-Militar-elemento civil, na Guerra Convencional; -Hacker e o Poder Cibernético: O primeiro elemento não militar em Guerra Não Convencional ${ }^{19}$. "(Liang/Chang p.08-67)

O Prof. Brick, acentua o emprego na integração dos conceitos de Logística de Defesa e Base Logística de Defesa, ao tema proposto em pesquisa:

"Logística de Defesa: refere-se de meios para compor as

Forças Armadas e sustentar suas operações, em quaisquer situações em que elas tenham que ser empregadas.

Base Logística de Defesa: é o agregado de capacitações tecnológicas, materiais e humanas, necessárias para 
desenvolver e sustentar a expressão militar, mas também

aprofundar o envolvimento no desenvolvimento da capacidade

e competitividade industrial do país como um todo. (BRICK,

p.06)

Igualmente, o Prof. Eurico Figueiredo ${ }^{21}$, reforça os Estudos Estratégicos ${ }^{22}$ ao tema proposto em artigo científico:

"Não se desenvolverá a ciência entre nós, como de resto em todo sistema democraticamente constituído, sem a organização e participação da comunidade em Políticas de Estado que possam ir ao encontro de seus objetivos e interesses. No caso dos Estudos Estratégicos não poder ser diferente."22(Eurico, p.290)

21-FIGUEIREDO, Eurico, “os Estudos Estratégicos, A Defesa Nacional e a Segurança Internacional”, p.290. 22-FIGUEIREDO, Eurico, Obra Citada, p. 273, Nota Explicativa: Os Estudos Estratégicos configuram “A expressão disciplinar do estudo científico do uso da força, do fenômeno bélico" (Proença Jr, 2004, p.114).

Nota Explicativa sobre Referências suplementares: A Linha de abordagem acerca da condução da Política e Estratégia de Defesa no Brasil a respeito das relações civis-militares e as determinantes domésticas e internacionais estão balizadas no Livro: "Política Externa e Poder Militar no Brasil” do Diplomata João Paulo Soares Alsina Júnior, (2009) constatando uma fecunda análise sobre a geopolítica contemporânea, discorrendo sobre a instrumentalidade do Poder Militar para a condução da política externa brasileira sobre os dias atuais. Para compreensão do Modelo e estrutura institucional adotada pelo Ministério da Defesa, cite-se a obra "Teory in Politic Science" de B.Guy Peters (1999); para identificação da ação do MD na construção da integração da Política de Defesa a da Política Externa, bem como a respectiva eficiência, eficácia e efetividade da Política e da Estratégia de Defesa é a obra de Joseph Nye ${ }^{16}$ (2012) sob título “O Futuro e o Poder”- Já os conceitos extraídos de "Hard Power" e "Soft Power" em Liang/Chang ${ }^{16}$ ver referencial teórico; Acompanhamento e avaliação de processos de Gestão da Política e da Estratégia de Defesa em perspectiva comparativa no âmbito Regional e Extra Regional. ver "De Dutra a Lula: A Condução e os determinantes da Política Externa Brasileira”, obra do Prof. Otávio Amorim Neto (2011).

Notas de Referência em Contribuição aos Estudos de Segurança Internacional e Defesa: 2-Livro Branco da Defesa, Ministério da Defesa, Governo Federal, 2013, Brasil.(p.39).

3-Estratégia Nacional de Defesa, Ministério da Defesa, Governo Federal, 2012, Brasil (p.21).

Notas de Referência em Referencial Bibliográfico: Aron, Raymond- Pensar a Guerra, Clausewitz: A Era Europeia. Brasília, Universidade de Brasília, UNB, (1986, p.136). Clausewitz, Carl Von: "Da Guerra" - São Paulo: Editora Martins Fontes, (1979. p.75).

Diniz, Eugênio "Epistemologia, História e Estudos Estratégicos: Clausewitz versus Keegan"; Artigo Científico aprovado para publicação em março de 2010, Contexto Internacional, Rio de Janeiro, Vol. 32 n. 1, (janeiro/junho de 2010, p. 54.).

Howard, Michael. Segundo Ensaios Introdutórios. In Clausewitz, Carl Von. Da Guerra: London Oxford University Press, (1984, p.470

Jomini, Antoine Henri de, Baron. The Art the War, London; Greenhill Books, (1992, p.25-35)

Keagan, John: "Uma História da Guerra- Tradução: Pedro Maia Soares-Companhia do Bolso, 2006, (p.11-12 e p.257-287.)".

Kaldor, Mary: New and Old Wars. 1 Ed. Stanford, University Stanford, 2001, (p.2-7).Lang, Q e Xingu, W. "A Guerra além dos limites conjecturas sobre a guerra e a tática na era da globalização", Beijing: Pala Literatura and. arts Publishing House, Fevereiro de 1999(. p.55-67). 


\section{REFERENCIAL METODOLÓGICO \\ 5.1 METODOLOGIA:}

O artigo utilizará o método qualitativo e quantitativo,ao mensurar os investimentos em Políticas de Defesa, Ciência e Tecnologia e Inovação, correspondente aos países em estudo,Brasil e França; as capacidades militares diante de contextos geopolíticos específicos; estudos acerca da dinâmica industrial e de inovação. Ademais, por meio de uma análise comparativa entre países em desenvolvimento e desenvolvidos,entre os quais,propõe-se a mensuração e integração do Orçamento em Defesa,ao conjugar os conceitos empregados em Logística,Economia e Engenharia de Defesa aplicada aos interesses da Soberania Nacional. Assim, o Prof. Bogossian ${ }^{23}$ delimita o escopo metodológico:Processo,Técnica e Ferramenta, visando o desenvolvimento e verificação de resultados obtidos e propectivos,tais como,o Submarino Riachuelo(S40) lançado em 2018,o Humaitá(S41) previsto para 2020,Tonelero(S42) em 2021 e o Agostura( S43) em 2022.

" Esse conjunto de obras que constitui a parte de infraestrutura industrial e de apoio do chamado Programa de Obtenção de Submarinos (PROSUB) cujo propósito é capacitar o Brasil a produzir e operar submarinos convencionais e com propulsão nuclear.Visando a concretização da independência na obtenção de submarinos, inclusive com propulsão nuclear, foi assinado acordo entre Brasil e França para adaptação do projeto Scorpène aos requisitos brasileiros, estabelecimento de requisitos para as instalações de fabricação e apoio e para assessoria de projeto e construção da parte não nuclear do submarino nuclear brasileiro." ${ }^{23}$ ( Bogossian, p.08)

\section{FONTES:}

Cadernos de Estudos Estratégicos - Edição Especial/ESG - Novembro de 2018, FINEP, IPEA, Ministério da Defesa, AMAZUL, Ministério da Ciência, Tecnologia, Inovação e Comunicações, Lei ${ }^{\circ} 12.598 / 2012$, Decreto $n^{\circ} 7.970 / 2013$, Decreto $n^{\circ} 8.122 / 2013$, Lei $\mathrm{n}^{\circ}$ 13.243 de 11/01/2016, Decreto $n^{\circ} 9.283$ de 07/02/2018 MP 870-01/01/2019- D.O. U e Logística de Defesa/UFF.

BRICK, Eduardo, "Logística de Defesa: Uma Subárea do Conhecimento de Importância Estratégica para as Ciências da Gestão, "artigo científico, maio/agosto de 2016: Revista Brasileira de Gestão e Desenvolvimento Regional, (p.301-331);

MELO Regiane-"Indústria de Defesa e Desenvolvimento Estratégico - Estudo Comparado Brasil e França": Fundação Alexandre de Gusmão, 2015.

ABREU DE MOURA, José Augusto, V Concurso de Teses sobre Defesa Nacional, categoria Doutorado: "A Estratégia Naval Brasileira no Pós- Guerra Fria - Uma Análise comparativa com foco nos submarinos", Tese de Doutorado, Niterói, 2012, UFF.

ANDRADE, Israel, ROCHA, Antônio, HILLEBRAND, Giovanni: Notatécnica-"Programa de Desenvolvimento de Submarinos como Programa de Estado", nº45,Diset,IPEA,Jan/2019. 
23-Bogossian,Francis-“A Defesa Nacional Brasileira”-Academia Nacional de Engenharia(ANE)- Artigo publicado no Jornal do Brasil - Edição de 06/07/2018, p.08.

\section{REFERÊNCIAS BIBLIOGRÁFICAS}

[1] ABREU DE MOURA, José Augusto, V Concurso de Teses sobre Defesa Nacional: categoria Doutorado: “A Estratégia Naval Brasileira no Pós-Guerra Fria - Uma Análise comparativa com foco nos submarinos", Tese de Doutorado, Niterói, 2012, UFF.

[2] ANDRADE, Israel, ROCHA, Antônio, HILLEBRAND, Giovanni: NotaTécnica"Programa de Desenvolvimento de Submarinos como Programa de Estado", n 45, Diset, IPEA, Jan/2019.

[3] BOGOSSIAN, Francis, Academia Nacional de Engenharia,(ANE)“A Defesa Nacional Brasileira”,Artigo publicado no Jornal do Brasil na edição de 06/07/2018,2018, p.08.

[4]BRASIL. Estratégia Nacional de Defesa: Paz e segurança para o Brasil. Brasília: Presidência da República, Casa Civil, 2008. . Política de Defesa Nacional. Brasília: Presidência da República, Casa Civil, 2005.

[6] Livro Branco de Defesa Nacional. Brasília: Presidência da República, Casa Civil, 2013.

[7] BASE de LOGISTICA de DEFESA NACIONAL. Brasília:

Presidência da República,

[8] BRICK, Eduardo, "Base de Logística de Defesa-Conceituação, Composição e Dinâmica de Funcionamento", artigo científico, UFF, 2016.

[9] . "A Gestão Estratégica da Defesa em Tempos de Paz.", artigo científico, Edição Especial CEE, artigo científico, ESG, 2018.

[10] __ . "Logística de Defesa: Uma Subárea do Conhecimento de Importância Estratégica para as Ciências da Gestão, artigo científico, maio/agosto de 2016: Revista Brasileira de Gestão e Desenvolvimento Regional, (p.301-331); [11] , FONSECA, Junior "PROSUB: Uma Política Pública de Defesa voltada para criação de instrumentos de dissuasão", artigo científico, 2018, Revista da Escola de Guerra Naval (ed. Português). [12] , "O Papel da Engenharia no Planejamento e Preparo de Defesa", Palestra organizada pela Academia Nacional de Engenharia e Clube de Engenharia, 29/07/2019, Auditório do 22 Andar, Clube de Engenharia, 2019.

[13] De CASTRO, Therezinha -“Geopolítica, Princípios, Meios e Fins.” Rio de Janeiro: Biblioteca do Exército, 1999.

[14] CUNHA Campos, Antônio Jorge: "Metodologia para elaboração do sistema integrado de avaliação de desempenho logístico”- Tese de Doutoramento, UFSC, 2004.

[15] CLAUSEWITZ, Carl Von: “Da Guerra” - São Paulo: Editora Martins Fontes, 1979. 
[16] DINIZ, Eugenio. Clausewitz,"O balanço ataque-defesa e a teoria das relações internacionais". Tese de Doutorado em Engenharia de Produção: Estudos Estratégicos- Coppe -UFRJ, Rio de Janeiro, 2002.

[17] FIGUEIREDO, Eurico, "os Estudos Estratégicos, A Defesa Nacional e a Segurança Internacional,",Horizontes das Ciências Sociais, In,MARTINS, C, B; R, LESSA (Coordenador), Anos, 2010.

[18] JOMINI, Antoine Henri de, Baron. The Art the War, London; Greenhill Books, 1992. [19] LESKE, Ariela Diniz Cordeiro. "Uma revisão sobre a inovação em defesa: do spindesligado ao spin-in". Revista de Economia Política vol. 38 n²(151). pp.377-391, AprilJune/2018

[20] MATTOS, Carlos de Meeira. "Geopolítica”. Rio de Janeiro: Editora FGV, 2011. Coedição com a Biblioteca do Exército. (03 Volumes)

[21] VILLAS PORTO, H.F.A."O Impacto do financiamento da FINEP na Inovação e capacitação Industrial para Defesa.”, Dissertação de Mestrado, UFF, 2016.

[22]THORPES, C "Pure Logistics. The Science of the war preparation", Nacional Defense University Press, $3^{\text {nd }}, 1986$. 